Supporting information

\title{
Au-Hemoglobin Loaded Platelet Alleviating Tumor Hypoxia and Enhancing the Radiotherapy Effect with Low-Dose X-ray
}

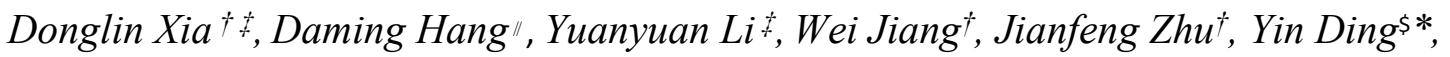 \\ Haiying $G u^{+*}$, Yong $H u^{\dagger *}$ \\ $\dagger$ Institute of Materials Engineering, College of Engineering and Applied Sciences, Nanjing University, \\ Jiangsu, 210093, P. R. China \\ ¥ School of Public Health, Nantong University, Nantong, Jiangsu 226019, P. R. China \\ \$State Key Laboratory of Analytical Chemistry for Life Science, School of Chemistry and Chemical \\ Engineering, Nanjing University, Nanjing, Jiangsu 210093, P. R. China \\ " Nantong Tumor Hospital, Nantong, Jiangsu, 226362, P.R. China
}

*Corresponding author. E-mail: dingyin@nju.edu.cn; hygu@ntu.edu.cn; hvyong@nju.edu.cn. 

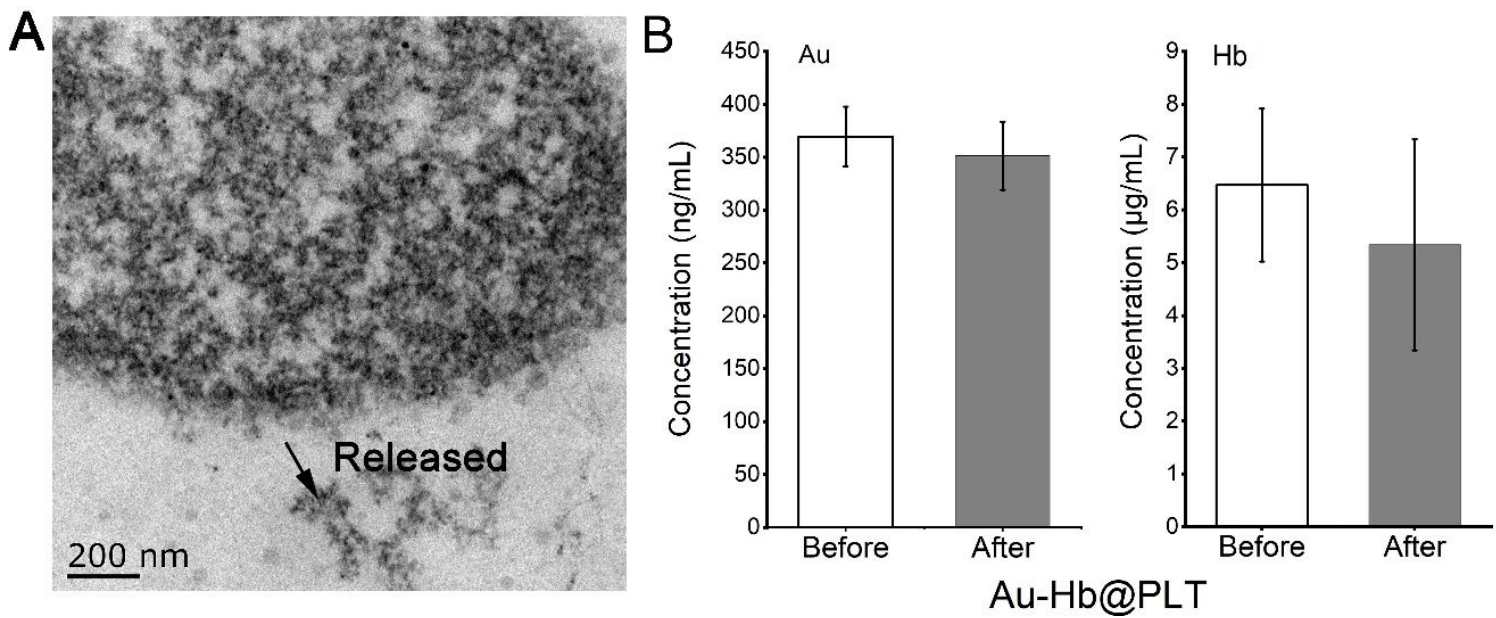

Figure S1. The change of Au-Hb@PLT pre- and post-activation. (A) TEM image of activated Au$\mathrm{Hb} @ \mathrm{PLT}$. (B) The changes of $\mathrm{Au}$ and $\mathrm{Hb}$ concentrations pre- and post-activation.

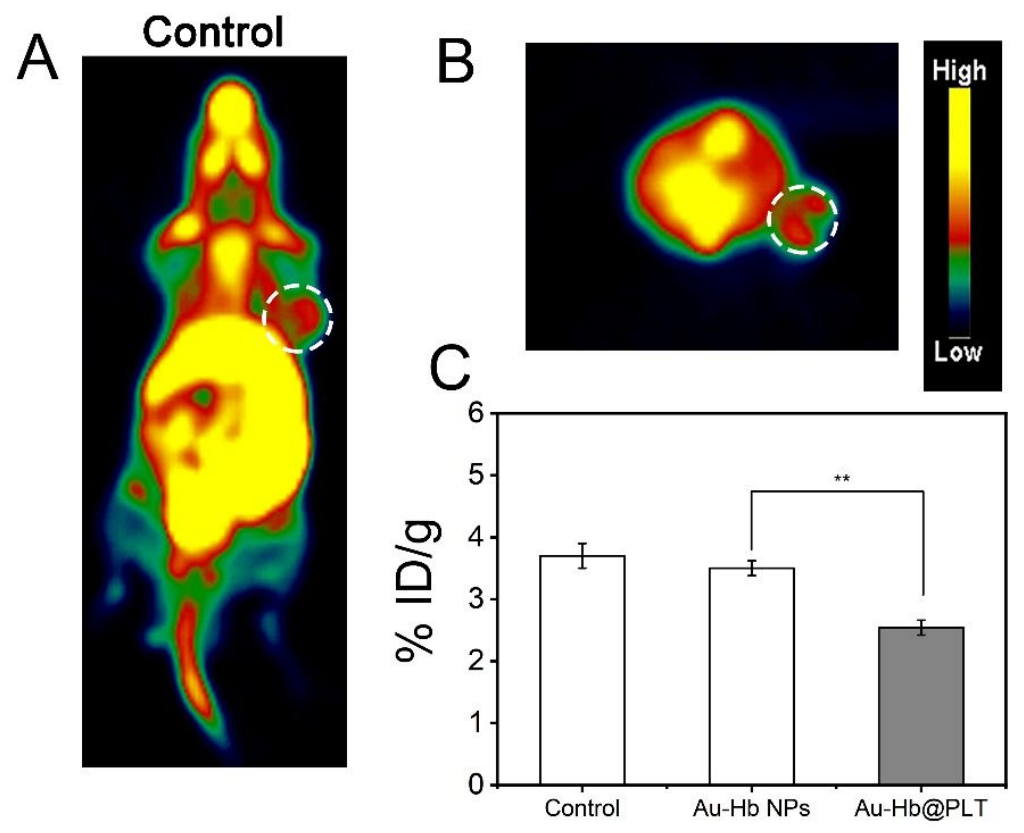

Figure S2. PET images of mice received PBS treatment. (A) 3D PET image of mice received PBS treatments. (B) Representative cross-sections differ in depth of the control group. (C) Normalized values (to the weight) in solid tumor regions. $* * P<0.01$. 


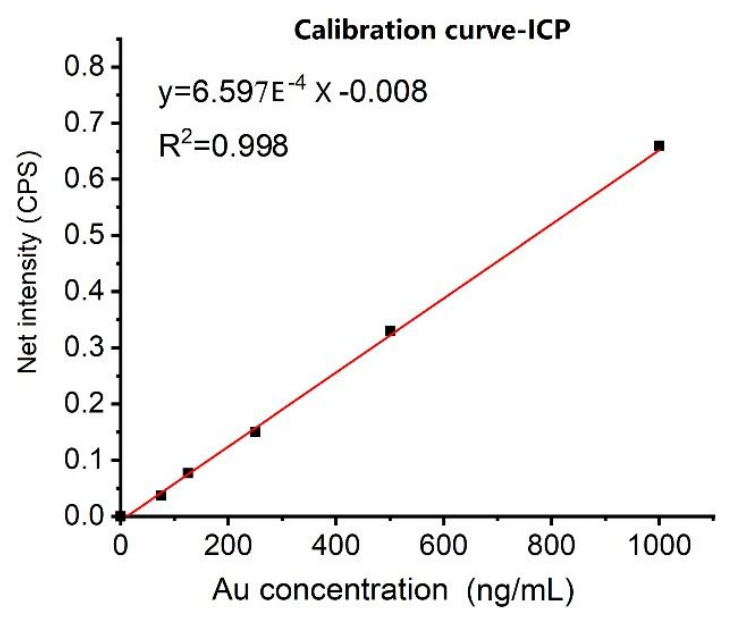

Figure S3. The standard curve for Au. The standard curve was a plot of the initial template quantity ( $\mathrm{x}$ axis) versus the threshold cycle (slope $=6.597 \mathrm{E}^{-4}$, $\mathrm{y}$ intercept $=-0.008, \mathrm{R}^{2}=0.998$ ).

Table S1. The amount added and the actual amount of Nano Au, Hb in Au-Hb@PLT

\begin{tabular}{ccccc}
\hline Nano Au & $\mathrm{Hb}$ & Platelet & \multicolumn{2}{c}{ Au-Hb@PLT } \\
\cline { 4 - 5 } $100 \mu \mathrm{g} / \mathrm{mL}$ & $10 \mathrm{mg} / \mathrm{mL}$ & & $74.78 \pm 8.25$ & $24.63 \pm 4.12$ \\
\hline $0.5 \mathrm{~mL}$ & $2.0 \mathrm{~mL}$ & $2.5 \mathrm{~mL}$ & $173.79 \pm 25.32$ & $30.14 \pm 2.56$ \\
$1.0 \mathrm{~mL}$ & $3.0 \mathrm{~mL}$ & $2.5 \mathrm{~mL}$ & $369.46 \pm 45.89$ & $6.47 \pm 0.66$ \\
$1.5 \mathrm{~mL}$ & $1.0 \mathrm{~mL}$ & $2.5 \mathrm{~mL}$ & & \\
\hline
\end{tabular}

Table S2. Factor level table

\begin{tabular}{cccc}
\hline Factor & Level 1 & Level 2 & Level 3 \\
\hline $\mathrm{Au}(\mathrm{ng} / \mathrm{mL})$ & 74.78 & 173.79 & 369.46 \\
$\mathrm{Hb}(\mu \mathrm{g} / \mathrm{mL})$ & 6.47 & 24.63 & 30.14 \\
\hline
\end{tabular}


Table S3. Orthogonal array

\begin{tabular}{cccc}
\hline Number & $\mathrm{Au}$ & $\mathrm{Hb}$ & $\begin{array}{c}\text { Inhibition ratio } \\
(\%)\end{array}$ \\
\hline$(1)$ & 1 & 1 & 45.39 \\
$(2)$ & 1 & 2 & 48.91 \\
$(3)$ & 1 & 3 & 50.49 \\
$(4)$ & 2 & 1 & 62.5 \\
$(5)$ & 2 & 2 & 45.39 \\
$(6)$ & 2 & 3 & 53.03 \\
$(7)$ & 3 & 1 & 68.02 \\
$(8)$ & 3 & 2 & 66.17 \\
$(9)$ & 3 & 3 & 45.39 \\
$\mathrm{~K}_{1}$ & 144.79 & 175.91 & \\
$\mathrm{~K}_{2}$ & 160.92 & 160.47 & \\
$\mathrm{~K}_{3}$ & 179.58 & 148.91 & \\
$\mathrm{k}_{1}$ & 48.26 & 58.64 & \\
$\mathrm{k}_{2}$ & 53.64 & 53.49 & \\
$\mathrm{k}_{3}$ & 59.86 & 49.64 & \\
$\mathrm{R}$ & 11.6 & 9 & \\
Main effect & $\mathrm{Au}$ & Optimal Combination & \\
\hline & & & \\
\hline
\end{tabular}

